EFING, Antônio Carlos; SANTOS, Fábio de Sousa; GUALBERTO, Stenio Castiel. Análise do contrato administrativo como instrumento da política nacional das relações de consumo. Revista Eletrônica Direito e Política, Programa de Pós-Graduação Stricto Sensu em Ciência Jurídica da UNIVALI, Itajaí, v.13, n.3, 30 quadrimestre de 2018. Disponível em: www.univali.br/direitoepolitica - ISSN 19807791

\title{
ANÁLISE DO CONTRATO ADMINISTRATIVO COMO INSTRUMENTO DA POLÍTICA NACIONAL DAS RELAÇÕES DE CONSUMO
}

\author{
ANALYSIS OF THE ADMINISTRATIVE CONTRACT AS AN INSTRUMENT OF THE \\ NATIONAL CONSUMER RELATIONS POLICY
}

Antônio Carlos Efing ${ }^{1}$

Fábio de Sousa Santos²

Stenio Castiel Gualberto 3

SUMÁRIO: Introdução; 1 A figura jurídica do consumidor no Direito brasileiro; 2 Licitação, mercado e vulnerabilidade; 3 Contrato administrativo, regime jurídico, prerrogativas da Administração e a Política nacional das relações de consumo; Considerações finais; Referências das fontes citadas.

\section{RESUMO}

O Estado participa do ambiente econômico, inclusive por meio da aquisição de bens e serviços. A caracterização de uma relação de consumo perpassa pela identificação da figura do consumidor e do reconhecimento de sua vulnerabilidade. O equilíbrio da relação da consumo, mandamento constitucional decorrente do princípio da igualdade, é o alvo das normas de ordem pública que a regulamentam, compensando o desequilíbrio existente na relação com os fornecedores. O objetivo do artigo é analisar se o regime de prerrogativas dos contratos administrativos, desenhados para acompanhar as emergências decorrentes da complexidade dos serviços públicos, é suficiente,para a correção da disparidade entre fornecedor e ente público, no que tange à caracterização da relação de consumo. A conclusão é no sentido de que o Estado pode figurar como consumidor em determinada relação contratual, e, mais além, que o Estado deve utilizar-se dessa condição como instrumento da Política Nacional das Relações de Consumo.

Palavras-chave: Estado; consumidor; contrato administrativo; políticas públicas.

\footnotetext{
1 Doutor em Direito das Relações Sociais pela PUC/SP; Professor titular da Pontifícia Universidade Católica do Paraná - PUCPR, onde leciona na graduação, especializações, mestrado e doutorado; Professor da Escola da Magistratura do Paraná; membro do Instituto dos Advogados do Paraná; Advogado militante em Curitiba/PR. E-mail: ace@eradv.com.br

2 Mestrando em Direito Econômico pela Pontifícia Universidade Católica do Paraná. Procurador do Estado de Rondônia. E-mail: fabiosantos@pge.ro.gov.br

3 Professor de Direito Penal da Faculdade Católica de Rondônia (FCR). Mestrando em Direito pela Pontifícia Universidade Católica do Paraná (PUCPR). Advogado. Porto Velho, Rondônia, Brasil. E-mail: stenio.castiel@fcr.edu.br.
} 
EFING, Antônio Carlos; SANTOS, Fábio de Sousa; GUALBERTO, Stenio Castiel. Análise do contrato administrativo como instrumento da política nacional das relações de consumo. Revista Eletrônica Direito e Política, Programa de Pós-Graduação Stricto Sensu em Ciência Jurídica da UNIVALI, Itajaí, v.13, n.3, 30 quadrimestre de 2018. Disponível em: www.univali.br/direitoepolitica - ISSN 19807791

\section{ABSTRACT}

The State participates in the economic environment, including through the acquisition of goods and services. The characterization of a consumption relationship identification of the consumer and recognition of their vulnerability. The balance of the relationship between consumption, deriving from the constitutional principle of equality, is the target of public policy that regulate, offsetting the imbalance in the relationship with suppliers. The article aims to verify if the regime of prerogatives of administrative contracts, designed to accompany the emergencies arising from the complexity of public services, is an undue simplification of the contractual theory, nor is it sufficient or objective to correct the disparity between supplier and public entity, in which characterization of the consumption relation. The conclusion is that the Government may appear as a consumer in a contractual relationship, and, further, that the Government Contracts must be used as an instrument of the National Policy for Consumer Affairs.

Keywords: State; consumer; administrative agreement; policies publics.

\section{INTRODUÇÃO}

Em um ambiente capitalista, é natural a ocorrência de uma interface contratual entre a Administração Pública e o mercado. Isso porque, ainda que com uma certa flexibilidade, há uma presunção de que o Estado não deve ocupar diretamente todo o espectro da atividade econômica.

A ação direta do Estado no Brasil enquanto agende demandante do mercado é bastante representativa sob o prisma econômico. No ano de 2016 foram realizados 105.658 (cento e cinco mil seiscentos e cinquenta e oito) procedimentos de contratações públicas ${ }^{4}$ diferentes somente no âmbito do Sistema Integrado de Serviços Gerais da União - SIASG, num importe econômico de mais de 51 bilhões de reais de contratações viabilizadas. ${ }^{5}$ Neste contexto, o presente artigo tem como objetivo investigar a possibilidade de a Administração Pública figurar em uma relação de consumo, no polo do consumidor. Isto é, avaliar a aplicabilidade do Código de Defesa do Consumidor às relações em que o Estado figura como adquirente de um bem exposto no mercado.

\footnotetext{
4 Entre as modalidades de pregão, tomada de preços, concorrência, concorrência internacional, convite e concurso, além de dispensas e inexigibilidades de licitação.

5 BRASIL. Sistema Integrado de Administração de Serviços Gerais. Ministério do Planejamento. Painel de Compras do Governo Federal. Disponível em: <http://paineldecompras.planejamento.gov.br /QvAJAXZfc/opendoc.htm?document=Painel de Compras.qvw\&host; >. Acesso em: 27 mar. 2017..
} 
EFING, Antônio Carlos; SANTOS, Fábio de Sousa; GUALBERTO, Stenio Castiel. Análise do contrato administrativo como instrumento da política nacional das relações de consumo. Revista Eletrônica Direito e Política, Programa de Pós-Graduação Stricto Sensu em Ciência Jurídica da UNIVALI, Itajaí, v.13, n.3, 30 quadrimestre de 2018. Disponível em: www.univali.br/direitoepolitica - ISSN 19807791

A análise proposta é dividida em três partes. A primeira parte visa identificar o conceito de consumidor, de acordo com o Ordenamento Brasileiro, bem como a extensão da política nacional das relações de consumo, mais especificamente naquilo que se verifica pertinente com a análise pretendida. Com isso mira-se avaliar a coerência de se vislumbrar o Estado como destinatário das normas previstas no conjunto normativo destinado a proteger o consumidor. A segunda parte visa esclarecer qual o papel do procedimento liciatório, seus pressupostos e a natureza do contrato administrativo. Nesta parte, tem-se como objetivo avaliar quais as consequências da realização do procedimento liciatório, especialmente no deslocamento de eixos de preponderância dentro da relação Estado-Fornecedor. A terceira e ultima parte discute, a partir da sobreposição dos conceitos discutidos nos tópicos anteriores, o encaixe do Estado-Adquirente na condição de consumidor.

É possível enxergar a Administração Pública como vulnerável? O Estado pode ser destinatário da política de proteção que ele mesmo deve implementar? 0 procedimento liciatório é suficiente para garantir igualdade entre o fornecedor e a Administração? A proteção oferecida pelo regime de prerrogativas do Contrato Administrativo não é suficiente? A isso se qualifica como respostas cuja busca se vê óbvia no trabalho proposto (embora as respostas possam não ser unânimes) e são essas algumas das perguntas que as próximas linhas tentam responder.

Mas é necessário ir além. Será, diante de todo o empuxo que pode produzir o Estado nas suas aquisições, que a contratação administrativa não poderia assumir um papel mais relevante, em uma visão ampliada, do que suprir as necessidades administrativas? 
EFING, Antônio Carlos; SANTOS, Fábio de Sousa; GUALBERTO, Stenio Castiel. Análise do contrato administrativo como instrumento da política nacional das relações de consumo. Revista Eletrônica Direito e Política, Programa de Pós-Graduação Stricto Sensu em Ciência Jurídica da UNIVALI, Itajaí, v.13, n.3, 30 quadrimestre de 2018. Disponível em: www.univali.br/direitoepolitica - ISSN 19807791

\section{A FIGURA JURÍDICA DO CONSUMIDOR NO DIREITO BRASILEIRO}

A Constituição Federal de 1988 traz, em diversos dispositivos, regramentos destinados à figura do consumidor. Seja como direito fundamental, ${ }^{6}$ seja como princípio da atividade econômica, ${ }^{7}$ a tônica da redação crua do texto constitucional é a de impor ao Estado sempre a posição de garantidor ou protetor da figura frágil do consumidor. É adequado, diante do perfil das normas constitucionais, falar que a Constituição Federal de 1988 inovou ao trazer a proteção do consumidor como princípio constitucional da ordem econômica. ${ }^{8}$

A análise pode ser aprofundada ainda mais, na medida em que o princípio da proteção do consumidor deve ser visto como derivativo do princípio constitucional da igualdade, na medida em que representa uma ruptura com o paradigma clássico da regulamentação contratual nacional, alicerçadas no individualismo e no voluntarismo. ${ }^{9}$ Ainda no terreno Constitucional, o Ato das Disposições Constitucionais Transitórias, em seu artigo 48,10 fixou prazo para o exercício de atividade legiferante, no sentido da elaboração do Código de Defesa do Consumidor.

A referida legislação, lei 8.078, foi promulgada em 11 de setembro de 1990, mas não encerra somente uma norma destinada a proteger o consumidor, mas sim "um Código para a sociedade de consumo, o qual institui normas e princípios para todos os agentes do mercado, os quais podem assumir papéis ora de fornecedores,

${ }^{6}$ BRASIL. Constituição (1988). Constituição Federal de 05 de outubro de 1988. Brasília, DF, Disponível em: <http://www.planalto.gov.br/ccivil_03/ constituicao/constituicaocompilado.htm>. Acesso em: 02 maio 2018. Art. 5', XXXII..

7 BRASIL. Constituição (1988). Constituição Federal de 05 de outubro de 1988. Brasília, DF, Disponível em: <http://www.planalto.gov.br/ccivil_03/ constituicao/constituicaocompilado.htm>. Acesso em: 02 maio 2018. Art. 170, V.

8 ROCHA, Ana Claudia Loyola da; CASTRO, Rodrigo Pironti Aguirre de. A proteção do consumidor como princípio da ordem econômica na Constituição de 1988. A\&C Revista de Direito Administrativo \& Constitucional, Belo Horizonte, ano 8, n. 32, p. 11-29, abr./jun. 2008. Disponível em: <http://www.bidforum.com.br/PDI0006.aspx?pdiCntd=53673>. Acesso em: 15 set. 2017. 20.

9 EFING, Antônio Carlos et al. (Org.). Direito do Consumo. 3. ed. Curitiba: Juruá, 2005. p.15 e

10 "Art. 48. O Congresso Nacional, dentro de cento e vinte dias da promulgação da Constituição, elaborará código de defesa do consumidor." 
EFING, Antônio Carlos; SANTOS, Fábio de Sousa; GUALBERTO, Stenio Castiel. Análise do contrato administrativo como instrumento da política nacional das relações de consumo. Revista Eletrônica Direito e Política, Programa de Pós-Graduação Stricto Sensu em Ciência Jurídica da UNIVALI, Itajaí, v.13, n.3, 30 quadrimestre de 2018. Disponível em: www.univali.br/direitoepolitica - ISSN 19807791

ora de consumidores". ${ }^{11}$ O CDC, em seu Art. $2^{\circ}$, optou por expor conceito legislativo de consumidor, definindo-o como "toda pessoa física ou jurídica que adquire ou utiliza produto ou serviço como destinatário final". É de se notar que a este conceito, a mesma lei equipara a consumidores ainda a coletividade interveniente na relações de consumo, ${ }^{12}$ vítimas de evento relacionado à relação de consumo bem como àqueles expostas às práticas de consumo. ${ }^{13} \mathrm{~A}$ leitura do código dá origem a duas principais correntes doutrinárias acerca da caracterização jurídica da figura do consumidor: a teoria finalista (ou subjetivista) e a teoria maximalista (ou objetiva).

A teoria finalista entende como consumidor aquele que remove o produto da cadeia produtiva, assumindo a posição de destinatário econômico e fático final do bem. O consumidor seria, portanto, aquele que assume a postura de usuário do objeto da relação de consumo sem utilizá-lo como insumo de atividade profissional. ${ }^{14}$ Esta linha de pensamento tende a excluir as pessoas jurídicas do conceito de consumidor assumindo duas generalizações: a primeira é de que pessoas jurídicas são, normalmente, estágios de uma cadeia produtiva; e a segunda é de que não são vulneráveis. ${ }^{15}$ Desta corrente, surge ainda a corrente do formalismo mitigado (ou aprofundado ou corrente mista), que admite como acobertados pelo Artigo $2^{\circ}$ do $C D C$ as pessoas físicas e jurídicas, ainda que não destinatárias finais do produto, estejam submetidas a uma situação concreta de vulnerabilidade. ${ }^{16} \mathrm{O}$

11 EFING, Antônio Carlos. Fundamentos do Direito Brasileiro das Relações de Consumo: Consumo, Desenvolvimento e Sustentabilidade. 3. ed. Curitiba: Juruá, 2011. p 56.

12 "Art. 20, parágrafo único. Equipara-se a consumidor a coletividade de pessoas, ainda que indetermináveis, que haja intervindo nas relações de consumo".

13 "Art. 17. Para os efeitos desta Seção, equiparam-se aos consumidores todas as vítimas do evento" e "Art. 29. Para os fins deste Capítulo e do seguinte, equiparam-se aos consumidores todas as pessoas determináveis ou não, expostas às práticas nele previstas".

14 MARQUES, Claudia Lima; BENJAMIN, Antonio Herman V.; BESSA, Leonardo Roscoe. Manual de Direito do Consumidor. 3. ed. São Paulo: RT, 2010. p. 85.

15 EFING, Antônio Carlos et al. (Org.). Direito do Consumo... p. 40.

16 EFING, Antônio Carlos. Fundamentos do Direito Brasileiro das Relações de Consumo: Consumo, Desenvolvimento e Sustentabilidade... p. 68. 
EFING, Antônio Carlos; SANTOS, Fábio de Sousa; GUALBERTO, Stenio Castiel. Análise do contrato administrativo como instrumento da política nacional das relações de consumo. Revista Eletrônica Direito e Política, Programa de Pós-Graduação Stricto Sensu em Ciência Jurídica da UNIVALI, Itajaí, v.13, n.3, 30 quadrimestre de 2018. Disponível em: www.univali.br/direitoepolitica - ISSN 19807791

Superior Tribunal de Justiça tem abarcado este último entendimento de forma reiterada. ${ }^{17}$

A necessidade de regulamentação das relações de consumo surge em virtude da massificação das relações contratuais, ocorrido em função do modelo de produção industrial da sociedade contemporânea. ${ }^{18}$ Tal modelo atribui ao fornecedor a unilateralidade do exercício de funções de mercado que o põe em posição de vantagem. Neste contexto, "a referência a um novo sujeito de direitos, o consumidor, é, antes de tudo, o reconhecimento de uma posição jurídica da pessoa numa determinada relação, a relação de consumo." ${ }^{19}$ Identifica-se aí um dos conceitos-chave para o entendimento da problemática: a vulnerabilidade. Tal caraceterística pode ser identificável em três diferentes formas: jurídica, técnica e fática. Antônio Carlos Efing leciona que:

A vulnerabilidade jurídica é a falta de conhecimentos jurídicos específicos, de contabilidade ou de economia (...). A vulnerabilidade fática ou socioeconômica, onde o ponto levado em consideração é o outro parceiro, ocorre quando o fornecedor, quer na sua posição de monopólio fático ou jurídico, que por $r$ seu grande poder econômico ou em razão da essencialidade do serviço, impõe suas condições para

\footnotetext{
${ }^{17}$ A título exemplificativo, o seguinte julgado ilustra bem o posicionamento da Corte: "Direito do Consumidor. Recurso especial. Conceito de consumidor. Critério subjetivo ou finalista. Mitigação. Pessoa Jurídica. Excepcionalidade. Vulnerabilidade. Constatação na hipótese dos autos. Prática abusiva. Oferta inadequada. Característica, quantidade e composição do produto. Equiparação (art. 29). decadência. Inexistência. Relação jurídica sob a premissa de tratos sucessivos. Renovação do compromisso. Vício oculto. - A relação jurídica qualificada por ser "de consumo" não se caracteriza pela presença de pessoa física ou jurídica em seus pólos, mas pela presença de uma parte vulnerável de um lado (consumidor), e de um fornecedor, de outro. - Mesmo nas relações entre pessoas jurídicas, se da análise da hipótese concreta decorrer inegável vulnerabilidade entre a pessoa-jurídica consumidora e a fornecedora, deve-se aplicar o CDC na busca do equilíbrio entre as partes. Ao consagrar o critério finalista para interpretação do conceito de consumidor, a jurisprudência deste STJ também reconhece a necessidade de, em situações específicas, abrandar o rigor do critério subjetivo do conceito de consumidor, para admitir a aplicabilidade do CDC nas relações entre fornecedores e consumidores-empresários em que fique evidenciada a relação de consumo."(BRASIL. Superior Tribunal de Justiça. Recurso Especial no 476.428 SC. Relator: Ministra Nancy Andrighi. Brasília, DF, 19 de abril de 2005. Dj. Brasília, 09 maio 2005.)
} 4.

18 NUNES, Luiz Antonio Rizzatto. Curso de direito do consumidor. São Paulo: Saraiva, 2004, p

19 MARQUES, Cáudia Lima; MIRAGEM, Bruno; LIXINSKI, Lucas. Desenvolvimento e Consumo: Bases para uma Análise da proteção do Consumidor como Direito Humano. In: PIOVESAN, Flávia; SOARES, Inês Virgínia Prado (Org.). Direito ao Desenvolvimento. Belo Horizonte: Fórum, 2010. p. 201-230. 
EFING, Antônio Carlos; SANTOS, Fábio de Sousa; GUALBERTO, Stenio Castiel. Análise do contrato administrativo como instrumento da política nacional das relações de consumo. Revista Eletrônica Direito e Política, Programa de Pós-Graduação Stricto Sensu em Ciência Jurídica da UNIVALI, Itajaí, v.13, n.3, 30 quadrimestre de 2018. Disponível em: www.univali.br/direitoepolitica - ISSN 19807791

contratar, de forma que o consumidor, por não ter muitas vezes outra alternativa, submete-se à tais condições. ${ }^{20}$

A vulnerabilidade técnica surge da necessidade de reconhecimento de que é o fornecedor, por imperativo do desenho do mercado, que possui o conhecimento e o controle de sua atividade. ${ }^{21}$ Observe-se que, neste ponto, a análise deve absterse de ter como ponto focal a relação pontual em si, mas observar que a atividade (e seus riscos) está sob controle do fornecedor. A evidente assimetria informacional, portanto, justifica o tratamento diferenciado.

A justaposição do panorama da vulnerabilidade deixa evidente a fragilidade das generalizações propostas pela teoria subjetivista. Embora possa-se verificar presunções legais para um ou outro lado, o equilíbrio e harmonia das relações de consumo demandam o reconhecimento inconteste da condição de vulnerável por parte do consumidor. ${ }^{22}$ É oportuna, portanto, a crítica à posição finalista, chamada de teoria maximalista ou objetiva. Para os adeptos desta corrente, a interpretação deve ser feita de "forma a abranger todas as possíveis relações de consumo".23 Observe-se que a condição de superioridade é não só legalmente atribuída, mas até mesmo desejada! Imagine o risco a que se submete alguém que utiliza um produto que nem seu fornecedor tem domínio de suas características.

É necessário relembrar que o Estado-contratante nem sempre dispõe de equidade, especialmente sob o ponto de vista técnico, com os agentes de mercado. Quando se fala dos pequenos municípios, não é demais sequer falar na hipossuficiência fática. ${ }^{24}$ Diante da noção de que o código visa disciplinar as relações de consumo, é adequado entender que a interpretação do artigo $2^{\circ}$ do CDC não deve ser restritiva, abrangendo toda e qualquer pessoa natural ou jurídica, pública ou privada, que trava relação de consumo, de qualquer objeto. ${ }^{25}$ Esta é a lente

\footnotetext{
${ }^{20}$ EFING, Antônio Carlos et al. (Org.). Direito do Consumo. p.38.

${ }^{21}$ EFING, Antônio Carlos et al. (Org.). Direito do Consumo. p.36 e 38.

22 EFING, Antônio Carlos et al. (Org.). Direito do Consumo. p 37.

23 EFING, Antônio Carlos et al. (Org.). Direito do Consumo. p 41.

24 PEREIRA JúNIOR, José Ricardo Britto Seixas. O Poder Público como Consumidor. Revista Virtual da Agu, Brasília, v. 80, n. 1000, p.1-5, set. 2008. Disponível em: <http://www.agu.gov .br/page/download/index/id/521844>. Acesso em: 28 mar. 2016.

25 É no mesmo sentido ainda a opinião de Othon Sidu e José Geral do Brito Filomeno.
} 
EFING, Antônio Carlos; SANTOS, Fábio de Sousa; GUALBERTO, Stenio Castiel. Análise do contrato administrativo como instrumento da política nacional das relações de consumo. Revista Eletrônica Direito e Política, Programa de Pós-Graduação Stricto Sensu em Ciência Jurídica da UNIVALI, Itajaí, v.13, n.3, 30 quadrimestre de 2018. Disponível em: www.univali.br/direitoepolitica - ISSN 19807791

conceitual, dentro do universo do direito das relações de consumo, que se fará a análise proposta no presente trabalho.

\section{LICITAÇÃO, MERCADO E VULNERABILIDADE}

As sociedades ocidentais modernas apontam como um dos valores mais relevantes a igualdade. Em resumo, tal mandamento principiológico encerra a ideia de que qualquer diferenciação pro movida pelo Estado deve derivar de fundamento idôneo para tal. ${ }^{26}$ No ambiente democrático, a igualdade e a impessoalidade exigem, que a concessão de benefício ou condição de obtenção de benefício a alguém, de forma singular e insusceptível de extensão a todos os interessados, deve ser precedida de algum tipo de validação por mecanismo procedimental. ${ }^{27}$ Seguindo esta linha a Constituição Federal brasileira elegeu, como pressuposto para as contratações públicas, a realização de procedimento de escolha da melhor proposta, assim denominado licitação. É o teor do art. 37, inciso XXI, ${ }^{28}$ que encontra ressonância na lei de licitações, especificamente, no art. 2o da Lei no $8.666 / 93 .^{29}$

Neste contexto, a Administração Pública é submetida a uma ritualística própria de atuação e, no caso das licitações no Brasil, é cadenciada de extensivamente prevista na legislação. ${ }^{30}$ A atividade administrativa em matéria contratual, portanto, tem a lei (latu sensu) como amparo de sua atuação e a impessoalidade como pressuposto de atuação, sendo a normatização que a baliza uma das garantias de tal caráter impessoal. Tal elemento tem assento constitucional, eis

26 MELLO, Celso Antônio Bandeira de. O conteúdo Jurídico do Princípio da Igualdade. 3. ed. São Paulo: Malheiros Editores Ltda, 2013.

27 SUNDFELD, Carlos Ari. Licitação e contrato administrativo: de acordo com as leis 8.666/93 e 8.883/94. 2 ed. São Paulo: Malheiros, 1995. p 15.

28 "Art. 37 - omissis; (...) XXI - ressalvados os casos específicos na legislação, as obras, serviços, compras e alienações serão contratados mediante processo de licitação pública que assegure igualdade de condições a todos os concorrentes, com cláusulas que estabeleçam obrigações de pagamento, mantidas as condições efetivas da proposta, nos termos da lei, o qual somente permitirá as exigências de qualificação técnica e econômica indispensáveis à garantia do cumprimento das obrigações". (grifos acrescidos).

29 "Art. 20 As obras e serviços, inclusive de publicidade, compras, alienações, concessões, permissões e locações da Administração Pública, quando contratadas com terceiros, serão necessariamente precedidas de licitação, ressalvadas as hipóteses previstas nesta lei".

30 FORTINI, Cristiana; MOTA, Fabrício. Corrupção nas licitações e contratações públicas: sinais de alerta segundo a Transparência Internacional. A\&C - Revista de Direito Administrativo \& Constitucional, Belo Horizonte, ano 16, n. 64, p. 93-113, abr,/j un. 2016. 
EFING, Antônio Carlos; SANTOS, Fábio de Sousa; GUALBERTO, Stenio Castiel. Análise do contrato administrativo como instrumento da política nacional das relações de consumo. Revista Eletrônica Direito e Política, Programa de Pós-Graduação Stricto Sensu em Ciência Jurídica da UNIVALI, Itajaí, v.13, n.3, 30 quadrimestre de 2018. Disponível em: www.univali.br/direitoepolitica - ISSN 19807791

que o caput do Artigo 37 da Constituição Federal, elenca, de forma expressa, como princípio da Administração Pública brasileira o "princípio da impessoalidade" ao lado dos demais princípios constitucionalmente afetos à Administração Pública nacional, tal qual o "princípio da eficiência administrativa", ${ }^{11}$ que veicula uma preocupação com o output das ações estatais.

A licitação é, portanto, instrumento para a operacionalização da isonomia e da impessoalidade, ofertando aos interessados igualdade de condições para a assunção da posição de contratado do Estado. ${ }^{32}$ Note-se que por "benefício" não se deve confundir por favores ou gratuidades. A oportunidade de contratar com a Administração - e daí obter lucro, faturamento ou simplesmente expertise ou penetração de mercado - já se constitui, por si, em posição de vantagem. ${ }^{33}$ No fundo, o papel da licitação é mimetizar uma transação de mercado dirigida de forma objetiva, já que ao Estado é imperioso escolher a priori, a partir dos valores que ordenam a atuação administrativa, em especial o interesse público e não a partir da autonomia da vontade.

O Estatuto das Licitações permite, em situações excepcionais, que se a realize a contratação sem a realização de prévio procedimento concorrencial eis que a realização do de tal procedimento "frustraria a realização adequada das funções estatais. O procedimento licitatório normal conduziria ao sacrifício dos fins buscados pelo Estado e não asseguraria uma contratação mais vantajosa". ${ }^{34}$ Essa flexibilização procedimental acompanha o necessário apego à principiologia da gestão pública. A licitação é uma operação econômica estatal que tenta mimetizar um ambiente de mercado, sendo intrínseco ao desenrolar deste processo o

31 GABARDO, Emerson. Princípio constitucional da eficiência administrativa. São Paulo: Dialética, 2001, p. 73 e ss.

32 NIEBUHR, Joel de Menezes. Licitação pública e contrato administrativo. 4. ed. rev. e ampl. Belo Horizonte: Fórum, 2015. p 34.

$33 \mathrm{O}$ mesmo raciocício pode ser aplicado è regra de aquisição de recursos humanos por parte da Administração Pública: o concurso público. Mesmo sendo a relação entre Estado e servidor uma relação sinalagmática, é a regra a efetivação de procedimento concorrencial para a posse em cargo público.

34 JUSTEN FILHO, Marçal. Comentários à lei de licitações e Contratos Administrativos. 17. ed., Editora Revista dos Tribunais: São Paulo, 2016. p 466. 
EFING, Antônio Carlos; SANTOS, Fábio de Sousa; GUALBERTO, Stenio Castiel. Análise do contrato administrativo como instrumento da política nacional das relações de consumo. Revista Eletrônica Direito e Política, Programa de Pós-Graduação Stricto Sensu em Ciência Jurídica da UNIVALI, Itajaí, v.13, n.3, 30 quadrimestre de 2018. Disponível em: www.univali.br/direitoepolitica - ISSN 19807791

dispêndio indireto de recursos na efetivação de todo o iter procedimental. ${ }^{35} \mathrm{Com}$ efeito, a diferença dos valores fundantes das atividades privada e pública, bem como a noção de que a legitimidade da ação do Estado também é conferida pela forma de sua atuação, impõe que a comparação entre os mecanismos e resultados da gestão pública e da gestão privada seja feita com as devidas reservas e com as réguas adequadas. Cumpre evidenciar que não se trata de rotular práticas isoladas como certas ou erradas, o que seria uma redução simplória das possibilidades científicas de comparação, mas de observar, na lição de Daniel Hachem, que:

[...] a gestão pública incorpora uma preocupação elevada por temas como a democracia, a responsabilidade e a igualdade, valores mais relevantes no âmbito público do que no setor empresarial, e uma orientação instrumental, a qual se traduz na aceitação de que a esfera pública compartilha com o setor privado a necessidade de alcançar seus objetivos da forma mais econômica e eficaz possível, mediante planejamento estratégico, estrutura administrativa adequada, pessoal motivado, técnicas idôneas para controlar recursos financeiros, humanos, materiais, etc. ${ }^{36}$

O que se observa é a existência de um procedimento demandado pela lei não constitui, em si, um mecanismo de elisão da vulnerabilidade do ente público, eis que não é nem fim, nem resultado colateral do procedimento licitatório em si, a superação da discrepância existente numa relação de consumo. O caráter instrumental do procedimento licitatório relaciona-se ao objeto contratual e aos valores caros para o Estado a não à transferência de uma posição dominante da relação. ${ }^{37}$

Merece nota o argumento no sentido da não aplicabilidade do CDC aos contratos administrativos, apontado por Marçal Justen Filho, de que é "a Administração é

35 BOCKMANN MOREIRA, Egon. GUIMARÃES, Fernando Vernalha. Licitação Pública: A lei Geral de Licitação - LGL e o Regime Diferenciado de contratação - RDC. Malheiros : São Paulo, 2012. Pág. 97.

36 HACHEM, Daniel Wunder. A concepção de gestão pública norte-americana e sua (in)compatibilidade com a realidade socioeconômica dos Estados latinoamericanos em desenvolvimento. Revista do Direito Unisc, Santa Cruz do Sul, v. 41, n. 1, p.41-64, dez. 2013. Disponível em: <http://online.unisc.br/ seer/index.php/direito/article/view/4115>. Acesso em: 08 mar. 2016.

37 MEIRELLES, Hely Lopes. Licitação e contrato Administrativo. 140 Edição. Malheiros : São Paulo, 2007, Pág. 125. 
EFING, Antônio Carlos; SANTOS, Fábio de Sousa; GUALBERTO, Stenio Castiel. Análise do contrato administrativo como instrumento da política nacional das relações de consumo. Revista Eletrônica Direito e Política, Programa de Pós-Graduação Stricto Sensu em Ciência Jurídica da UNIVALI, Itajaí, v.13, n.3, 30 quadrimestre de 2018. Disponível em: www.univali.br/direitoepolitica - ISSN 19807791

quem define a prestação a ser executada pelo particular, assim como as condições que disciplinarão a relação jurídica. ${ }^{38}$ Entretanto e com a devida venia ao peso da autoridade em matéria de licitações apontada, não parece ter razão o ilustre administrativista.

O procedimento licitatório é comumente dividido em fase interna ou preparatória (aquela que congrega os atos de planejamento e preparação ao certame) e a fase externa, que é aquela que se inicia com a publicação do instrumento convocatório e se conclui com a homologação. São diversas as normas que encontram fundamento de validade na noção constitucional já destacada, de onde destacamse a Lei 8.666 de 21 de junho de 1993 (Lei Geral de Licitações), a Lei no 10.520 de 17 de julho de 2012, (que criou a modalidade licitatória denominada pregão), a Lei 12.462 de 04 de agosto de 2011 (Lei do Regime Diferenciado de Contratações) e a lei 13.303, de 30 de junho de 2016 (Lei das Estatais). Neste cenário, o pregão é a modalidade licitatória incluída no ordenamento com o advento da Lei n. 10.520/2002, tendo como móvel de adoção "a desburocratização do sistema de compras administrativas, bem como a diminuição dos custos"39. 0 citado diploma legislativo, no seu artigo 10, parágrafo primeiro, traz conceito de "bem comum" como sendo "aqueles cujos padrões de desempenho e qualidade possam ser objetivamente definidos pelo edital, por meio de especificações usuais no mercado".

A fase interna (ou preparatória) é o ponto nevrálgico da contratação pública e tem como ponto focal a definição da necessidade estatal a ser satisfeita por meio do objeto contratual. ${ }^{40} \mathrm{O}$ momento procedimental onde é moldado o encaixe estatal ao qual tentarão acoplar-se as interessadas é este, sendo consubstanciando, em tal modalidade licitatória, no documento denominado "Termo de Referência". A

38 JUSTEN FILHO, Marçal. Comentários à lei de licitações e Contratos Administrativos. 17. ed., Editora Revista dos Tribunais: São Paulo, 2016. p 1274 .

39 MORAIS, Isaias Fonseca. Manual de Direito Administrativo. Teoria e Prática. Juruá: Belo Horizonte, 2010, p. 320.

40 GUERRA, Evandro Martins; NAVES, Luís Emílio Pinheiro. Políticas públicas na fase interna d licitação. Fórum de Contratação e Gestão Pública - FCGP, Belo Horizonte, ano 11, n. 131, nov. 2012. Disponível em:<http://www.bidforum.com.br/bid/PDI0006.a spx?pdiCntd=82308>. Acesso em: 20 set. 2017 
EFING, Antônio Carlos; SANTOS, Fábio de Sousa; GUALBERTO, Stenio Castiel. Análise do contrato administrativo como instrumento da política nacional das relações de consumo. Revista Eletrônica Direito e Política, Programa de Pós-Graduação Stricto Sensu em Ciência Jurídica da UNIVALI, Itajaí, v.13, n.3, 30 quadrimestre de 2018. Disponível em: www.univali.br/direitoepolitica - ISSN 19807791

interpretação que a doutrina tem dado para o referido dispositivo é literal, senão extensiva, sendo no sentido de que "praticamente todos os bens e serviços foram considerados comuns; poucos, na verdade, estarão fora da relação, o que significa que o pregão será adotado em grande escala".41 Tal modalidade, em 2014, já respondia por $94 \%$ (noventa e quatro por cento) dos procedimentos realizados no âmbito da União, e mais de $91 \%$ dos gastos com aquisições. ${ }^{42}$

O posicionamento do Tribunal de Contas da União não foge ao apontado, ressaltando que o fato das características do objeto não serem de conhecimento geral, não tem o condão de impossibilitar a sua descrição segundo especificações usuais do mercado. ${ }^{43}$ A Administração, em regra, não se presta a criar uma inflexão tamanha no mercado interessado, ao ponto de fazer com que suas necessidades sejam satisfeitas por um objeto único, exclusivo e customizado, absolutamente fora do mercado. Ao que parece, este fato é reconhecido de modo expresso pela Lei 10.520/2002 quando estipula que são as especificações oferecidas pelo mercado que nortearão as decisões administrativas no pregão. A este ponto, fica evidente que o Estado é sujeito exposto às práticas de mercado tanto quanto qualquer particular ao qual ele se obrigou a proteger pela legislação consumerista, sendo o procedimento licitatório insuficiente contrabalancear a assimetria existente na relação de consumo.

41 CARVAlHO FILHO, José dos Santos. Manual de Direito Administrativo. $25^{\circ}$ Edição. São Paulo: Atlas, 2012, p. 304.

42 BRASIL. Portal Brasil. Ministério do Planejamento. Pregão eletrônico resulta em economia de $\mathbf{R} \$ \mathbf{7 , 8}$ bilhões. Disponível em: <http://www.brasil.gov.br/governo/2015/03/ pregao eletronico- resulta-em-economia-de-r-7-8-bilhoes>. Acesso em: 21 set. 2017.

43 (...) A utilização da modalidade pregão é possível, nos termos da Lei no 10.520/2002, sempre que o objeto da contratação for padronizável e disponível no mercado, independentemente de sua complexidade. (...) 3. Nos termos do Decreto no 4.342/2002, é possível a utilização do registro de preços para contratação de bens e serviços de informática (BRASIL. Tribunal de Contas da União. Acórdão no 2172, Ata 40/2008. Relator: Ministro Augusto Nardes. Brasília, DF, 01 de outubro de 2008.) 
EFING, Antônio Carlos; SANTOS, Fábio de Sousa; GUALBERTO, Stenio Castiel. Análise do contrato administrativo como instrumento da política nacional das relações de consumo. Revista Eletrônica Direito e Política, Programa de Pós-Graduação Stricto Sensu em Ciência Jurídica da UNIVALI, Itajaí, v.13, n.3, 30 quadrimestre de 2018. Disponível em: www.univali.br/direitoepolitica - ISSN 19807791

\section{CONTRATO ADMINISTRATIVO, REgime JURÍdICO, PRERROgATIVAS DA ADMINISTRAÇÃO E A POLÍTICA NACIONAL DAS RELAÇÕES DE CONSUMO}

O contrato administrativo um é mecanismo de interface entre o Estado e o mercado, com vistas ao aproveitamento de eficiências mútuas. Jessé Torres e Marinês Dotti chegam a apontar que a norma Constitucional estabelece a preferência à execução indireta, realizando uma "opção estratégica pela contratação de empresas do mercado". ${ }^{44}$ No Estado Social, caracterizado pelo avanço da superação do modelo do ato administrativo unilateral, influenciado pelo incentivo à consensualidade, a figura do contrato passa a ter importância equivalente à do ato administrativo. ${ }^{45} \mathrm{~A}$ definição da doutrina clássica acerca do contrato administrativo passa pela referência ao seu regime jurídico:

A expressão Contrato administrativo é reservada para designar tão somente os ajustes que a Administração, nessa qualidade, celebra com pessoas físicas ou jurídicas, públicas ou privadas, para a consecução de fins públicos, segundo regime jurídico de direito público. ${ }^{46}$

O regime Jurídico do contrato administrativo é feito, prioritariamente, pelas disposições da lei 8.666/93. Fernando Dias Menezes de Almeida identifica a ocorrência de uma simplificação no processo de importação da teoria contratual francesa para o Brasil, na medida em reconhece-se a essência do contrato administrativo apenas como a existência de cláusulas exorbitantes. ${ }^{47}$ Em apertada síntese, a definição de "cláusulas exorbitantes" - um tanto tautológica, diga-se é de que são aquelas que não se veem comuns ou mesmo possíveis nos contratos

44 PEREIRA JUNIOR, Jessé Torres; DOTTI, Marinês Restelatto. Políticas públicas nas licitações e contratações administrativas. 2. ed. Belo Horizonte: Fórum, 2012. p 39.

45 FORTINI, Cristiana. Aspectos relevantes dos contratos administrativos. Fórum de Contratação e Gestão Pública FCGP, Belo Horizonte, ano 7, n. 83, nov. 2008. Disponível em: <http://www.bidforum.com.br/bid/PDI0006.aspx?pdiCntd=55668>. Acesso em: 21 set. 2017

46 DI PIETRO, Maria Sylvia Zanella. Direito Administrativo, 23 Edição. São Paulo : Atlas, 2010. Pág. 251.

47 ALMEIDA, Fernando Dias Menezes de. Contrato administrativo no Brasil: aspectos críticos da teoria e da prática. Revista de Contratos Públicos - RCP, Belo Horizonte, ano 1, n.1, mar./ago. 2012. 
EFING, Antônio Carlos; SANTOS, Fábio de Sousa; GUALBERTO, Stenio Castiel. Análise do contrato administrativo como instrumento da política nacional das relações de consumo. Revista Eletrônica Direito e Política, Programa de Pós-Graduação Stricto Sensu em Ciência Jurídica da UNIVALI, Itajaí, v.13, n.3, 30 quadrimestre de 2018. Disponível em: www.univali.br/direitoepolitica - ISSN 19807791

efetivados no regime jurídico de direito privado, ${ }^{48}$ estando estas normas fundamentalmente descritas no art. 58 da lei $8.666 / 93 .{ }^{49} \mathrm{~A}$ leitura do dispositivo normativo permite identificar, que o dispositivo pode ser simplificado, sem qualquer prejuízo, na permissão da mutabilidade do objeto contratual, sendo as demais tão somente repetições desnecessárias de poderes extracontratuais da Administração.

Eros Grau já alerta para a necessidade de reconhecer que a expressão "Ordem Econômica" é plurissêmica, comportando tanto um sentido de ordem de fato como um conceito relativo ao ordenamento jurídico. ${ }^{50} \mathrm{Um}$ destes regramentos é o contrato administrativo, que se consubstancia, por si, em uma técnica de produção normativa. A crítica de Fernando Dias Menezes de Almeida é ainda mais pertinente quando esclarece que o regime das cláusulas exorbitantes previsto na lei 8.666/93 foi pensado para os contratos relativos a serviços públicos. ${ }^{51}$

Sendo as ações do Estado sempre direcionadas à promoção do desenvolvimento eis que este é valor supremo e objetivo da República, 52 as interações entre Estado

48 ARÊDES, Sirlene Nunes. As cláusulas exorbitantes e a distinção dos contratos da Administração em contratos administrativos e contratos de direito privado. Revista de Direito Administrativo, v. 253, p. 173-198, jan./abr. 2010.

49 "Art. 58. O regime jurídico dos contratos administrativos instituído por esta Lei confere à Administração, em relação a eles, a prerrogativa de:

I - modificá-los, unilateralmente, para melhor adequação às finalidades de interesse público, respeitados os direitos do contratado;

II - rescindi-los, unilateralmente, nos casos especificados no inciso I do art. 79 desta Lei;

III - fiscalizar-lhes a execução;

IV - aplicar sanções motivadas pela inexecução total ou parcial do ajuste;

V - nos casos de serviços essenciais, ocupar provisoriamente bens móveis, imóveis, pessoal e serviços vinculados ao objeto do contrato, na hipótese da necessidade de acautelar apuração administrativa de faltas contratuais pelo contratado, bem como na hipótese de rescisão do contrato administrativo.

§ 1ํ As cláusulas econômico-financeiras e monetárias dos contratos administrativos não poderão ser alteradas sem prévia concordância do contratado.

$\S 2$ ○ Na hipótese do inciso I deste artigo, as cláusulas econômico-financeiras do contrato deverão ser revistas para que se mantenha o equilíbrio contratual."

50 GRAU, Eros Roberto. A Ordem Econômica na Constituição de 1988: Interpretação e Crítica. São Paulo: Malheiros, 2008. p 65.

51 ALMEIDA, Fernando Dias Menezes de. Contrato administrativo no Brasil: aspectos críticos da teoria e da prática...

52 FOLLONI, André. A complexidade ideológica, jurídica e política do desenvolvimento sustentável 
EFING, Antônio Carlos; SANTOS, Fábio de Sousa; GUALBERTO, Stenio Castiel. Análise do contrato administrativo como instrumento da política nacional das relações de consumo. Revista Eletrônica Direito e Política, Programa de Pós-Graduação Stricto Sensu em Ciência Jurídica da UNIVALI, Itajaí, v.13, n.3, 30 quadrimestre de 2018. Disponível em: www.univali.br/direitoepolitica - ISSN 19807791

e Sociedade devem ser observadas pela lente da Teoria da Complexidade. que as interações humanas seguem um padrão não linear, tendo como inerência a incerteza. Duas são as características de sistemas complexos que valem destacar aqui: a primeira é a causalidade recursiva; a segunda, a emergência. A não linearidade dos sistemas complexos faz com que os mecanismos alterações de suas características sejam dinâmicos. Existem "gatilhos" ou pontos críticos que criam ciclos virtuosos ou ativam determinados comportamentos sistêmicos. A esse fenômeno dá-se o nome de causalidade recursiva. ${ }^{53} \mathrm{~A}$ emergência decorre da impossibilidade de identificar claramente os padrões do sistema, de modo a estabelecer um liame de causalidade claro entre uma intervenção e seu resultado. ${ }^{54}$

Neste contexto, o cenário fático (ordem econômica) acerca dos serviços públicos é cambiante, sendo necessário fornecer aos instrumentos que regulam tais ações a necessária flexibilidade com vistas à garantia, fundamentalmente, do equilíbrio econômico - financeiro da relação. ${ }^{55}$ É importante ressaltar que este ponto do debate só faz sentido a partir da ótica da teoria maximalista, eis que o Estado é uma entidade essencialmente vetorial. É um intermediário por excelência, na medida em que o princípio da supremacia do interesse público promove uma "alocação ao Estado do dever primordial de promoção dos objetivos republicanos do Artigo $3^{\circ}$ da constituição de $1988^{\prime \prime} .{ }^{56}$ A simplificação e a adoção legal de um regime jurídico impertinente transpassam a ideia equivocada acerca do regime de sujeição quando confrontados com a aplicabilidade do CDC. Isso porque as prerrogativas administrativas, muito embora forneçam importante ferramental

e a necessidade de compreensão interdisciplinar do problema. Revista Mestrado em Direito (UNIFIEO), $\quad$ v. $41, \quad$ p. $63-91, \quad 2014 . \quad$ Disponível em: <http://www.andrefolloni.com.br/fotos/1426543042_863-3210-1-PB.pdf>. Acesso em: 28 de dez. 2015.

53 ROGERS, Patricia J.. Using Programme Theory to Evaluate Complicated and Complex Aspects of Interventions. Evaluation, [s.I.], v. 14, n. 1, p.29-48, jan. 2008.

54 VEIGA, José Eli da. A emergência socioambiental. São Paulo: Senac, 2007. p. 113.

55 ALMEIDA, Fernando Dias Menezes de. Contrato administrativo no Brasil: aspectos críticos da teoria e da prática.

56 GABARDO, Emerson. O princípio da supremacia do interesse público sobre o interesse privado como fundamento do Direito Administrativo Social. Revista de Investigações Constitucionais, Curitiba, vol. 4, n. 2, p. 95-130, maio/ago. 2017. 
EFING, Antônio Carlos; SANTOS, Fábio de Sousa; GUALBERTO, Stenio Castiel. Análise do contrato administrativo como instrumento da política nacional das relações de consumo. Revista Eletrônica Direito e Política, Programa de Pós-Graduação Stricto Sensu em Ciência Jurídica da UNIVALI, Itajaí, v.13, n.3, 30 quadrimestre de 2018. Disponível em: www.univali.br/direitoepolitica - ISSN 19807791

para a gestão pública, não são suficientes para afastar com segurança a vulnerabilidade das figuras estatais, especialmente quando se observa a problemática sob o prisma da vulnerabilidade técnica. ${ }^{57}$

O Estado não é uma figura onisciente e onipotente (e nem deve ser) devendo aceitar que, às vezes, sua intervenção é prejudicial. ${ }^{58} \mathrm{Na}$ relação de consumo, em regra, não faz sentido ao Estado a transferência do conhecimento técnico acerca do objeto contratual, de modo que o agente de mercado permanece superposto ao ente estatal na gangorra da assimetria informacional. É importante notar que o art. 54 da Lei 8.666/93 faz referência aos preceitos aplicáveis aos contratos administrativos. ${ }^{59}$ Mais do que simplesmente invocar a necessidade de diálogo das fontes, de modo a romper com o raciocínio excludente, é imperioso relembrar que o Código de Defesa do Consumidos, enquanto texto regulatório das relações de consumo, é norma de ordem pública. ${ }^{60}$

É importante e necessário ir além. O administrador público deve, na busca do objeto imediato que se pretende contratar, promover os valores caros ao Estado e incentivar, possibilitar e promover o desenvolvimento dos aspectos mediatos à contratação em si, utilizando-se da contratação pública como instrumento multilateral de atuação da Administração Pública. Nas palavras de Daniel Ferreira "o legislador trouxe à tona, mais uma vez, a necessidade de percepção que o ganho social é tão ou mais importante que o benefício econômico-financeiro no

57 Muito embora, talvez, fosse salutar vivenciar realidade diversa, o fato é que a Administração Pública brasileira ainda não atingiu níveis desejáveis de maturidade no exercício de suas funções (OLIVEIRA, Nelson do Vale. O amadorismo como traço distintivo da burocracia federal brasileira. 2009. 212 f. Tese (Doutorado) - Curso de Sociologia, Departamento de Sociologia, Universidade de Brasília, Brasilia, 2009. Disponível em: <http://repositorio.unb.br/ bitstream/10482/18548/1/2009_NelsondoValeOliveira.pdf>. Acesso em: 23 mar. 2017.), e ainda que assim não o fosse, talvez não seja dado ao Estado deter todo o conhecimento.

58 DUNLOP, Caire; RADAELLI, Claudio. Overcoming Ilusions of Controle: How to Nudge and Teach Regulatory Humility. In: ALEMANNO, Alberto; SIBONY, Anne-lise. Nudging in Europe: What Can EU Law Learn from Behavioural Sciences. Londres: Bloomsburry Press, 2015. Cap. 6. p. 139-158.

59 "Art. 54. Os contratos administrativos de que trata esta Lei regulam-se pelas suas cláusulas e pelos preceitos de direito público, aplicando-se-lhes, supletivamente, os princípios da teoria geral dos contratos e as disposições de direito privado."

60 ROCHA, Ana Claudia Loyola da; CASTRO, Rodrigo Pironti Aguirre de. A proteção do consumidor como princípio da ordem econômica na Constituição de $1988 .$. 
EFING, Antônio Carlos; SANTOS, Fábio de Sousa; GUALBERTO, Stenio Castiel. Análise do contrato administrativo como instrumento da política nacional das relações de consumo. Revista Eletrônica Direito e Política, Programa de Pós-Graduação Stricto Sensu em Ciência Jurídica da UNIVALI, Itajaí, v.13, n.3, 30 quadrimestre de 2018. Disponível em: www.univali.br/direitoepolitica - ISSN 19807791

entorno das licitações". ${ }^{61}$ Marçal Justen Filho consigna que a linha mestra estabelecida pela legislação nacional para os procedimentos licitatórios é a busca da "contratação mais vantajosa". ${ }^{2}$ Por "vantajosa", não comporta entender "barata" de modo que o interesse patrimonial do Estado não é o único a ser levado em conta.

A implementação das políticas públicas deve ser feita por meio da coordenação das ferramentas à disposição do ente público para a realização de determinadas "metas coletivas conscientes". 63 Tendo o Código de Defesa do Consumidor listado como princípio da Política Nacional de Relações de Consumo, a ação governamental pela presença do Estado no mercado de consumo, é natural pensar a implementação de tais política pública, evidentemente complexa, de maneira multifacetada. ${ }^{64} \mathrm{Em}$ todo este contexto, o contrato administrativo figura como inegável instrumento para a execução da Política nacional das Relações de Consumo, muito embora não esteja expressamente listado nos incisos do Art. $5^{\circ}$ da Lei 8.078/90, encaixando-se na cláusula geral prevista na parte final do caput. ${ }^{65}$

\section{CONSIDERAÇÕES FINAIS}

O Estado é um relevante ator do cenário econômico, seja atuando na regulação do mesmo, seja participando diretamente de operações econômicas, como provedor de serviços e bens ou como contratante.

A licitação, enquanto instrumental estatal para a garantia da isonomia, e o regime jurídico do contrato administrativo, não tem como consequência necessária a

61 FERREIRA, Daniel. A licitação pública no Brasil e sua finalidade legal: a promoção do desenvolvimento nacional sustentável. Belo Horizonte: Fórum, 2012.

62 JUSTEN FILHO, Marçal. Comentários à lei de licitações e Contratos Administrativos. 17. ed., Editora Revista dos Tribunais: São Paulo, 2016. p. 466.

63 DALLARI BUCCI, Maria Paula. Direito Administrativo e Políticas Públicas. São Paulo: Saraiva, 2002, p. 241

64 "Art. 40 A Política Nacional das Relações de Consumo tem por objetivo o atendimento das necessidades dos consumidores, o respeito à sua dignidade, saúde e segurança, a proteção de seus interesses econômicos, a melhoria da sua qualidade de vida, bem como a transparência e harmonia das relações de consumo, atendidos os seguintes princípios: II - ação governamental no sentido de proteger efetivamente o consumidor: (...) c) pela presença do Estado no mercado de consumo;"

65 "Art. 5 Para a execução da Política Nacional das Relações de Consumo, contará o poder público com os seguintes instrumentos, entre outros." 
EFING, Antônio Carlos; SANTOS, Fábio de Sousa; GUALBERTO, Stenio Castiel. Análise do contrato administrativo como instrumento da política nacional das relações de consumo. Revista Eletrônica Direito e Política, Programa de Pós-Graduação Stricto Sensu em Ciência Jurídica da UNIVALI, Itajaí, v.13, n.3, 30 quadrimestre de 2018. Disponível em: www.univali.br/direitoepolitica - ISSN 19807791

dissolução da assimetria que caracteriza a relação de consumo, mantendo o mercado fornecedor ator em posição de superioridade.

Na medida em que as normas que disciplinam o consumo, com destaque ao Código de Defesa do Consumidor, são normas de ordem pública, sua aplicação aos contratos administrativos sequer chega a ser supletiva, sendo o reconhecimento da possibilidade do ente público figurar no polo vulnerável de uma relação de consumo, nada mais do que a preservação do sentido lógico do ordenamento.

Para além do debate posto, observado o sentido de que os instrumentos estatais devem prestar à persecução dos valores e interesses caros ao interesse público e não somente ao interesse patrimonial imediato. O contrato administrativo, servindo de veículo para uma relação de consumo, deve servir também de instrumento de efetivação dos princípios da política nacional das relações de consumo.

\section{REFERÊNCIAS DAS FONTES CITADAS}

ALEMANNO, Alberto; SIBONY, Anne-lise. Nudging in Europe: What Can EU Law

Learn from Behavioural Sciences. Londres: Bloomsburry Press, 2015.

ALMEIDA, Fernando Dias Menezes de. Contrato administrativo no Brasil: aspectos críticos da teoria e da prática. Revista de Contratos Públicos - RCP, Belo Horizonte, ano 1, n.1, mar./ago. 2012.

ARÊDES, Sirlene Nunes. As cláusulas exorbitantes e a distinção dos contratos da Administração em contratos administrativos e contratos de direito privado. Revista de Direito Administrativo, v. 253, p. 173-198, jan./abr. 2010.

BOCKMANN MOREIRA, Egon. GUIMARÃES, Fernando Vernalha. Licitação Pública: A lei Geral de Licitação - LGL e o Regime Diferenciado de contratação - RDC. Malheiros : São Paulo, 2012.

BRASIL. Constituição (1988). Constituição Federal de 05 de outubro de 1988. Brasília, DF, Disponível em: <http://www.planalto.gov.br/ccivil_03/ constituicao/constituicaocompilado.htm>. Acesso em: 02 maio 2018. 
EFING, Antônio Carlos; SANTOS, Fábio de Sousa; GUALBERTO, Stenio Castiel. Análise do contrato administrativo como instrumento da política nacional das relações de consumo. Revista Eletrônica Direito e Política, Programa de Pós-Graduação Stricto Sensu em Ciência Jurídica da UNIVALI, Itajaí, v.13, n.3, 30 quadrimestre de 2018. Disponível em: www.univali.br/direitoepolitica - ISSN 19807791

BRASIL. Portal Brasil. Ministério do Planejamento. Pregão eletrônico resulta em economia de $\mathbf{R} \mathbf{7 , 8}$ bilhões. Disponível em: <http://www.brasil.gov.br/governo/2015/03/ pregao -eletronico- resulta-emeconomia-de-r-7-8-bilhoes>. Acesso em: 21 set. 2017.

BRASIL. Sistema Integrado de Administração de Serviços Gerais. Ministério do Planejamento. Painel de Compras do Governo Federal. Disponível em: <http://paineldecompras.planejamento.gov.br/QvAJAXZfc/opendoc.htm?docume nt=Painel de Compras.qvw\&host; > . Acesso em: 27 mar. 2017.

BRASIL. Superior Tribunal de Justiça. Recurso Especial no 476.428 SC. Relator: Ministra Nancy Andrighi. Brasília, DF, 19 de abril de 2005. Dj. Brasília, 09 maio 2005.

BRASIL. Tribunal de Contas da União. Acórdão no 2172, Ata 40/2008. Relator: Ministro Augusto Nardes. Brasília, DF, 01 de outubro de 2008.

CARVAlHo Filho, José dos Santos. Manual de Direito Administrativo. $25^{\circ}$ Edição. São Paulo: Atlas, 2012.

DALLARI BUCCI, Maria Paula. Direito Administrativo e Políticas Públicas. São Paulo: Saraiva, 2002.

DI PIETRO, Maria Sylvia Zanella. Direito Administrativo, $23^{\circ}$ Edição. São Paulo : Atlas, 2010.

EFING, Antônio Carlos. Fundamentos do Direito Brasileiro das Relações de Consumo: Consumo, Desenvolvimento e Sustentabilidade. 3. ed. Curitiba: Juruá, 2011.

EFING, Antônio Carlos et al. (Org.). Direito do Consumo. 3. ed. Curitiba: Juruá, 2005.

FERREIRA, Daniel. A licitação pública no Brasil e sua finalidade legal: a promoção do desenvolvimento nacional sustentável. Belo Horizonte: Fórum, 2012. 
EFING, Antônio Carlos; SANTOS, Fábio de Sousa; GUALBERTO, Stenio Castiel. Análise do contrato administrativo como instrumento da política nacional das relações de consumo. Revista Eletrônica Direito e Política, Programa de Pós-Graduação Stricto Sensu em Ciência Jurídica da UNIVALI, Itajaí, v.13, n.3, 30 quadrimestre de 2018. Disponível em: www.univali.br/direitoepolitica - ISSN 19807791

FOLLONI, André. A complexidade ideológica, jurídica e política do desenvolvimento sustentável e a necessidade de compreensão interdisciplinar do problema. Revista Mestrado em Direito (UNIFIEO), v. 41, p. 63-91, 2014. Disponível em: <http://www.andrefolloni.com.br/fotos/1426543042_863-3210-1-PB.pdf>.

Acesso em: 28 de dez. 2015.

FORTINI, Cristiana. Aspectos relevantes dos contratos administrativos. Fórum de Contratação e Gestão Pública FCGP, Belo Horizonte, ano 7, n. 83, nov. 2008. Disponível em: <http://www.bidforum.com.br/bid/PDI0006.aspx? pdiCntd $=55668>$. Acesso em: 21 set. 2017

FORTINI, Cristiana; MOTA, Fabrício. Corrupção nas licitações e contratações públicas: sinais de alerta segundo a Transparência Internacional. A\&C - Revista de Direito Administrativo \& Constitucional, Belo Horizonte, ano 16, n. 64, p. 93-113, abr,/j un. 2016.

GABARDO, Emerson. Princípio constitucional da eficiência administrativa. São Paulo: Dialética, 2001.

GABARDO, Emerson. O princípio da supremacia do interesse público sobre o interesse privado como fundamento do Direito Administrativo Social. Revista de Investigações Constitucionais, Curitiba, vol. 4, n. 2, p. 95-130, maio/ago. 2017.

GUERRA, Evandro Martins; NAVES, Luís Emílio Pinheiro. Políticas públicas na fase interna d licitação. Fórum de Contratação e Gestão Pública - FCGP, Belo Horizonte, ano 11, n. 131, nov. 2012. Disponível em:<http://www.bidforum.com.br/bid/PDI0006.a spx?pdiCntd=82308>. Acesso em: 20 set. 2017.

GRAU, Eros Roberto. A Ordem Econômica na Constituição de 1988: Interpretação e Crítica. São Paulo: Malheiros, 2008.

HACHEM, Daniel Wunder. A concepção de gestão pública norte-americana e sua (in)compatibilidade com a realidade socioeconômica dos Estados latinoamericanos em desenvolvimento. Revista do Direito Unisc, Santa Cruz do Sul, v. 41, n. 1, 
EFING, Antônio Carlos; SANTOS, Fábio de Sousa; GUALBERTO, Stenio Castiel. Análise do contrato administrativo como instrumento da política nacional das relações de consumo. Revista Eletrônica Direito e Política, Programa de Pós-Graduação Stricto Sensu em Ciência Jurídica da UNIVALI, Itajaí, v.13, n.3, 30 quadrimestre de 2018. Disponível em: www.univali.br/direitoepolitica - ISSN 19807791

p.41-64, dez. 2013. Disponível em: <http://online.unisc.br/ seer/index.php/direito/article/view/4115>. Acesso em: 08 mar. 2016.

JUSTEN FILHO, Marçal. Comentários à lei de licitações e Contratos Administrativos. 17. ed., Editora Revista dos Tribunais: São Paulo, 2016.

MARQUES, Claudia Lima; BENJAMIN, Antonio Herman V.; BESSA, Leonardo Roscoe. Manual de Direito do Consumidor. 3. ed. São Paulo: RT, 2010.

MEIRELLES, Hely Lopes. Licitação e contrato Administrativo. 140 Edição. Malheiros : São Paulo, 2007.

MELLO, Celso Antônio Bandeira de. O conteúdo Jurídico do Princípio da Igualdade. 3. ed. São Paulo: Malheiros Editores Ltda, 2013.

MORAIS, Isaias Fonseca. Manual de Direito Administrativo. Teoria e Prática. Juruá: Belo Horizonte, 2010, p. 320.

NIEBUHR, Joel de Menezes. Licitação pública e contrato administrativo. 4. ed. rev. e ampl. Belo Horizonte: Fórum, 2015.

NUNES, Luiz Antonio Rizzatto. Curso de direito do consumidor. São Paulo: Saraiva, 2004.

OLIVEIRA, Nelson do Vale. O amadorismo como traço distintivo da burocracia federal brasileira. 2009. 212 f. Tese (Doutorado) - Curso de Sociologia, Departamento de Sociologia, Universidade de Brasília, Brasilia, 2009. Disponível em: <http://repositorio.unb.br/bitstream/10482/18548/1/2009_NelsondoValeOliveira . pdf>. Acesso em: 23 mar. 2017.

PEREIRA JUNIOR, Jessé Torres; DOTTI, Marinês Restelatto. Políticas públicas nas licitações e contratações administrativas. 2. ed. Belo Horizonte: Fórum, 2012.

PEREIRA JúNIOR, José Ricardo Britto Seixas. O Poder Público como Consumidor. Revista Virtual da Agu, Brasília, v. 80, n. 1000, p.1-5, set. 2008. Disponível em: 
EFING, Antônio Carlos; SANTOS, Fábio de Sousa; GUALBERTO, Stenio Castiel. Análise do contrato administrativo como instrumento da política nacional das relações de consumo. Revista Eletrônica Direito e Política, Programa de Pós-Graduação Stricto Sensu em Ciência Jurídica da UNIVALI, Itajaí, v.13, n.3, $3^{\circ}$ quadrimestre de 2018. Disponível em: www.univali.br/direitoepolitica - ISSN 19807791

<http://www.agu.gov .br/page/download/index/id/521844>. Acesso em: 28 mar. 2016.

PIOVESAN, Flávia; SOARES, Inês Virgínia Prado (Org.). Direito ao Desenvolvimento. Belo Horizonte: Fórum, 2010.

ROCHA, Ana Claudia Loyola da; CASTRO, Rodrigo Pironti Aguirre de. A proteção do consumidor como princípio da ordem econômica na Constituição de 1988. A\&C Revista de Direito Administrativo \& Constitucional, Belo Horizonte, ano 8, n. 32, p. 11-29, abr./jun. 2008. Disponível em: <http://www.bidforum.com.br/PDI0006.aspx?pdiCntd=53673>. Acesso em: 15 set. 2017.

ROGERS, Patricia J.. Using Programme Theory to Evaluate Complicated and Complex Aspects of Interventions. Evaluation, [s.I.], v. 14, n. 1, p.29-48, jan. 2008.

SUNDFELD, Carlos Ari. Licitação e contrato administrativo: de acordo com as leis 8.666/93 e 8.883/94. 2 ed. São Paulo: Malheiros, 1995.

VEIGA, José Eli da. A emergência socioambiental. São Paulo: Senac, 2007.

Recebido em: 29/08/2018

Aprovado em: 02/09/2018 